\title{
Exigência de Treonina para Pintos de Corte no Período de 1 a 21 Dias de Idade ${ }^{1}$
}

\section{Rita da Trindade Ribeiro Nobre Soares ${ }^{2}$, Luiz Fernando Teixeira Albino ${ }^{3}$, Horácio Santiago Rostagno ${ }^{3}$, Gardênia Holanda Cabral ${ }^{4}$, Débora C. O Carvalho ${ }^{5}$}

\begin{abstract}
RESUMO - Este experimento foi realizado para determinar a exigência de treonina para frangos de corte, no período de 1 a 21 dias de idade, e avaliar o efeito de diferentes níveis de treonina sobre a excreção de ácido úrico em frangos de corte. Um mil e duzentos pintos foram distribuídos ao caso em esquema fatorial $6 x 2$, sendo seis níveis de treonina total $(0,73 ; 0,77 ; 0,81 ; 0,85 ; 0,89 ;$ e $0,93 \%)$ e dois sexos, com cinco repetições de 20 aves cada. Consumo de ração, ganho de peso, conversão alimentar e níveis plasmáticos de ácido úrico foram avaliados. Ensaio biológico usando o método da coleta total de excreta foi realizado para avaliar o efeito dos níveis de treonina sobre a excreção de ácido úrico. Efeito linear positivo e negativo dos níveis de treonina sobre o ganho de peso de machos e fêmeas, respectivamente, e efeito quadrático sobre o consumo de ração e conversão alimentar de machos e fêmeas foram observados. Os níveis de treonina não influenciaram os níveis plasmáticos de ácido úrico nas aves, e não foi observado efeito dos níveis de treonina sobre a excreção de ácido úrico. Os níveis de 0,86 e $0,73 \%$ de treonina total e 0,73 e $0,62 \%$ de treonina digestível foram suficientes para máximo desempenho de machos e fêmeas, respectivamente.
\end{abstract}

Palavras-chave: ácido úrico, aminoácido, frangos de corte, treonina digestível

\section{Threonine Requirement for Broiler Chicks From 1 to 21 Days of Age}

\begin{abstract}
This experiment was carried out to determine the threonine requirement for broilers chicks from 1 to 21 days of age and to evaluate the effect of different threonine levels on the uric acid excretion in broilers. One thousand and two hundred broiler chicks were randomly allotted to a $6 x 2$ factorial arrangement, being six levels of total threonine $(.73, .77, .81, .85, .89$, and .93\%) and two sexes, with five replicates of 20 birds each. Feed intake, weight gain, feed:gain ratio and plasma uric acid levels were evaluated. A biologic trial using the total collection of feces method was conducted to evaluate the effect of threonine level on the uric acid excretion. There were linear positive and negative effects of the threonine levels on males and females weight gain, respectively, and quadratic effect on feed intake and feed:gain ratio of males and female. The threonine levels did not influence the uric acid plasmatic levels in the birds, and was not observed effect of threonine levels on the uric acid excretion. The levels of .86\% and .73\% of total threonine and .73\% and .62\% of digestible threonine were sufficient to maximize performance of males and females, respectively.
\end{abstract}

Key Words: uric acid, amino acid, broiler, digestible threonine

\section{Introdução}

A alimentação constitui cerca de $70 \%$ dos custos da produção avícola e a fonte de proteína constitui parte substancial destes custos. Assim, muitos esforços são feitos no sentido de racionalizar o uso de proteína nas rações, reduzindo-o sem influenciar o desempenho das aves, ou buscando suplementações que possam representar melhoria na eficiência de sua utilização.

Com o avanço da biotecnologia na área de produção de aminoácidos sintéticos, torna-se possível a utilização de rações com menores níveis de proteína bruta. Os primeiros aminoácidos a serem suplementados e empregados em larga escala na indústria foram metionina e lisina; outros, entretanto, estão sendo introduzidos no mercado a preços competitivos, principalmente o triptofano e a treonina (COLNAGO, 1992).

Com a possível redução do nível de proteína bruta da ração, associada à disponibilidade de aminoácidos sintéticos no mercado, as pesquisas são orientadas no sentido de estabelecer proporções ideais de aminoácidos essenciais em relação à lisina. Trata-se do perfil da proteína ideal, possibilitando redução da excreção de nitrogênio e conseqüente aumento da eficiência de utilização da proteína.

Visando a aplicação do conceito da proteína ideal, várias pesquisas são conduzidas no sentido de melhor

\footnotetext{
${ }^{1}$ Parte da Tese de Doutorado do primeiro autor. Pesquisa financiada pela FAPEMIG.

2 Zootecnista, DS.

3 Professor do Departamento de Zootecnia da UFV.

${ }^{4}$ Estudante de Doutorado, UFV.

${ }^{5}$ Estudante de Zootecnia, UFV.
} 
definir as exigências e a digestibilidade dos aminoácidos nos ingredientes utilizados na alimentação de frangos de corte (HAN e PARSONS, 1990; HOLSHEIMER e VEERKAMP, 1992; HAN E BAKER, 1994; PUPA, 1995; e FISCHER JR. et al., 1998).

Metionina, lisina e treonina são, respectivamente, os três primeiros aminoácidos limitantes nas rações das aves (FERNANDEZ et al., 1994). Há bastante informações sobre as exigências de metionina e lisina para frangos de corte, sendo a treonina o menos estudado.

Aumento da exigência de treonina, com incremento de proteína bruta da ração, foi verificado por ROBINS (1987), que utilizou rações contendo 15 e $20 \%$ de proteína, obtendo valores de 0,58 e $0,75 \%$ de treonina, respectivamente, para performance ótima dos frangos. Esses resultados são semelhantes aos encontrados por RANGEL-LUGO et al. (1994), que também utilizaram dois níveis de proteína bruta, 20 e $25 \%$, encontrando exigência de 0,76 e $0,90 \%$ de treonina, respectivamente. De fato, pesquisas mostram que as exigências de aminoácidos estão diretamente relacionadas com o nível de proteína bruta da ração (ROGERS e PESTI, 1990; AUSTIC et al., 1992).

De acordo com o NRC (1994), a exigência de treonina para a fase inicial de criação de frangos de corte (1 a 21 dias de idade) é de $0,80 \%$, em ração com $23 \%$ de proteína bruta, enquanto ROSTAGNO et al. (1992) recomendam $0,24 \%$ de treonina/ $1000 \mathrm{kcal}$ de energia metabolizável.

Dentro deste contexto, o objetivo do presente trabalho foi determinar a exigência de treonina para frangos de corte no período de 1 a 21 dias de idade e verificar o efeito de diferentes níveis de treonina sobra a excreção de ácido úrico.

\section{Material e Métodos}

O experimento foi conduzido na seção de Avicultura do Departamento de Zootecnia da Universidade Federal de Viçosa.

Foram utilizados 1200 pintos de 1 dia de idade, linhagem comercial, distribuídos ao acaso em um arranjo fatorial $6 \times 2$, sendo dois sexos e seis níveis de suplementação de L-treonina $(0,00 ; 0,04 ; 0,08 ; 0,12$; 0,16 ; e $0,20 \%$, resultando em total de 0,$73 ; 0,77 ; 0,81$; 0,$85 ; 0,89$; e $0,93 \%$ de treonina) com cinco repetições, com 20 aves cada., totalizando 60 unidades experimentais. As aves foram pesadas no início do experimento.
A ração basal (Tabela 1) foi formulada para atender às exigências preconizadas por ROSTAGNO et al. (1992), exceto as de treonina. As demais rações experimentais foram obtidas por meio da suplementação de L-treonina na ração basal, em substituição ao inerte. As aves receberam água e ração ad libitum.

Ao final do experimento ( 21 dias de idade), as aves e as sobras de ração foram pesadas e calculadas as médias de ganho de peso, consumo de ração e conversão alimentar. Também foram coletados 2-ml de sangue por meio de punção cardíaca de duas aves em cada unidade experimental. O sangue foi centrifugado, obtendo-se o soro no qual foi feita a análise de ácido úrico pelo método enzimático utilizando kits comerciais.

Concomitantemente, foi realizado um ensaio biológico para verificar a influência dos níveis de treonina sobre a excreção de ácido úrico. Foram utilizados 480 pintos de corte de 10 dias de idade, distribuídos aos acaso em esquema fatorial 6x2 (seis níveis de treonina e dois sexos) com quatro repetições. As aves foram alojadas em baterias metálicas e alimentados com as mesmas rações experimentais.

Após cinco dias de adaptação, as excretas de todas as unidades experimentais foram coletadas em bandejas cobertas com plástico durante cinco dias. O material recolhido foi colocado em sacos plásticos, pesado e armazenado em congelador, até o período final de coleta. No final do período, as amostras foram descongeladas, devidamente reunidas por repetição e homogeneizadas. Retiraramse de cada amostra alíquotas de 400 a $500 \mathrm{~g}$, as quais foram colocadas em estufa ventilada, à temperatura de $55^{\circ} \mathrm{C}$, por 48 horas para secagem. Posteriormente, as amostras foram moídas em moinho de bola e usadas para análise do teor de ácido úrico por intermédio do método enzimático, utilizando kits comerciais. As amostras foram preparadas de acordo com a metodologia descrita por MARQUARDT (1983). A porcentagem de ácido úrico nas excretas foi calculada a partir dos valores encontrados.

Todos os dados foram submetidos à análise estatística utilizando-se o programa SAEG (Sistema para Análise Estatística e Genética), desenvolvido pela UNIVERSIDADE FEDERAL DE VIÇOSA -UFV (1982). Foi feita análise de regressão utilizando-se efeitos lineares e quadráticos para determinação da exigência de treonina. 
124 Rev. bras. zootec.

Tabela 1 - Composição percentual da ração basal Table 1- Percentage composition of basal diet

\begin{tabular}{|c|c|}
\hline \multicolumn{2}{|l|}{ Ingredient } \\
\hline Amido (Starch) & 34,62 \\
\hline Sorgo - baixo tanino & 23,250 \\
\hline \multicolumn{2}{|l|}{ Sorghum - low tannin } \\
\hline Farelo de soja & 20,000 \\
\hline \multicolumn{2}{|l|}{ Soybean meal } \\
\hline Glúten de milho & 12,000 \\
\hline \multicolumn{2}{|l|}{ Corn gluten meal } \\
\hline Farinha de carne e ossos & 4,000 \\
\hline $\begin{array}{l}\text { Meat and bone meal } \\
\text { Óleo de soja }\end{array}$ & 2,000 \\
\hline \multicolumn{2}{|l|}{ Soybean oil } \\
\hline \multicolumn{2}{|l|}{ Dicalcium phosphate } \\
\hline Calcário (Limestone) & 0,601 \\
\hline DL - Metionina & 0,206 \\
\hline \multicolumn{2}{|l|}{ DL - Methionine } \\
\hline L-Lisina.HCl & 0,550 \\
\hline \multicolumn{2}{|l|}{ L-Lysine. $\mathrm{HCl}$} \\
\hline \multicolumn{2}{|l|}{ L-Tryptophan } \\
\hline Sal (Salt) & 0,323 \\
\hline Premix vitamínico $^{1}$ & 0,100 \\
\hline \multicolumn{2}{|l|}{ Vitamin premix } \\
\hline \multicolumn{2}{|l|}{ Mineral premix } \\
\hline Cloreto de colina $(60 \%)$ & 0,050 \\
\hline \multicolumn{2}{|l|}{ Choline chloride } \\
\hline Bacitracina de zinco $10 \%$ & 0,050 \\
\hline \multicolumn{2}{|l|}{ Zinc bacitracin } \\
\hline Antioxidante-BHT & 0,010 \\
\hline \multicolumn{2}{|l|}{ Antioxidant } \\
\hline Areia lavada & 1,501 \\
\hline \multicolumn{2}{|l|}{ Washed sand } \\
\hline Total & 100,000 \\
\hline Energia metabolizável $\mathrm{kcal} / \mathrm{kg}^{\mathrm{c}}$ & 3160 \\
\hline \multicolumn{2}{|l|}{ Metabolizable energy } \\
\hline Proteína bruta (Crude protein), $\% \mathrm{~d}$ & 21,15 \\
\hline Lisina (Lysine), $\% \mathrm{c}$ & 1,24 \\
\hline Metionina + Cistina (Methionine + Cystine),$\% \mathrm{c}$ & 0,90 \\
\hline Treonina total (Total threonine), $\%{ }^{\mathrm{c}}$ & 0,73 \\
\hline Treonina digestível, $\% \mathrm{c}$ & 0,62 \\
\hline \multicolumn{2}{|l|}{ Digestible threonine } \\
\hline Cálcio (Calcium), $\%$ c & 1,00 \\
\hline Fósforo disponível ,\%c & 0,45 \\
\hline \multicolumn{2}{|l|}{ Disponible phosphorus } \\
\hline \multirow{2}{*}{\multicolumn{2}{|c|}{ 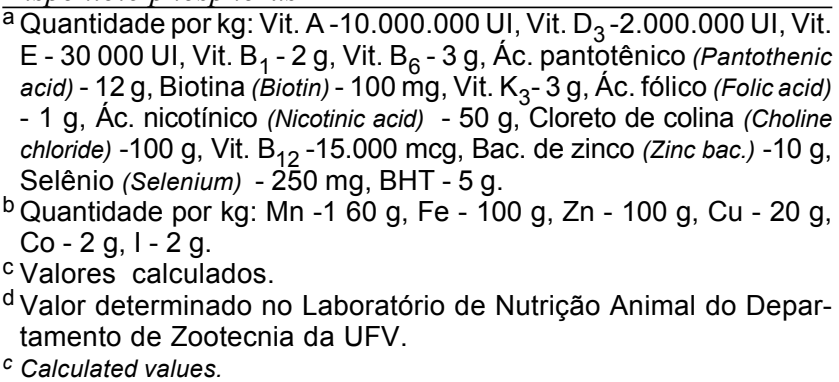 }} \\
\hline & \\
\hline $\begin{array}{l}{ }^{c} \text { Calculated values. } \\
{ }^{d} \text { Value determined in the Animal Nutrition Laboratory } \\
\text { Department of UFV. }\end{array}$ & Animal Science \\
\hline
\end{tabular}

${ }^{d}$ Value determined in the Animal Nutrition Laboratory of Animal Science Department of UFV.

\section{Resultados e Discussão}

As médias de consumo de ração, ganho de peso e conversão alimentar de machos e fêmeas, de acordo com os níveis de treonina da ração, são apresentadas na Tabela 2. Observou-se efeito quadrático dos níveis de treonina sobre o consumo de ração dos machos $(\mathrm{P}<0,01)$ e fêmeas $(\mathrm{P}<0,05)$ e efeito linear positivo e negativo $(\mathrm{P}<0,05)$ sobre o ganho de peso de machos e fêmeas, respectivamente. Os efeitos lineares sobre o ganho de peso das aves não permitiram definir qual o melhor nível de treonina, embora seja observado na Tabela 2 que o melhor ganho de peso foi apresentado por machos e fêmeas que receberam, respectivamente, ração contendo $0,93 \mathrm{e}$ $0,73 \%$ de treonina. Entretanto, com relação à conversão alimentar, foi observado efeito quadrático dos níveis de treonina para machos $(\mathrm{P}<0,01)$ e fêmeas $(\mathrm{P}<0,05)$. A exigência de treonina para machos, de acordo com os resultados de conversão alimentar, foi estimada por meio da determinação do ponto de mínimo, em $0,86 \%$. No caso da conversão alimentar das fêmeas, o efeito quadrático negativo observado não tem sentido biológico para este tipo de característica. O melhor resultado foi apresentado pelas fêmeas que receberam ração com $0,73 \%$ de treonina, o que está de acordo com os resultados de ganho de peso, sugerindo que não houve deficiência de treonina na ração basal utilizada.

Os resultados encontrados neste experimento discordam dos encontrados por ROBINS (1987) e RANGEL-LUGO et al. (1994), que estabeleceram níveis de 0,75 e $0,76 \%$, respectivamente, correspondentes à exigência de treonina para frangos de corte na fase de 1 a 21 dias de idade. Entretanto, observando as médias de conversão alimentar dos machos, percebe-se que o melhor resultado foi apresentado pelas aves que receberam ração com $0,77 \%$ de treonina, valor este próximo dos supracitados.

Há vários fatores que podem ser considerados para explicar os resultados encontrados neste experimento. Os trabalhos citados na literatura (ROBINS, 1987; SMITH e WALDROUP, 1988; RANGELLUGO et al., 1994) foram realizados utilizando rações basais com níveis de treonina bem abaixo dos recomendados, o que possibilita observar melhor efeito da suplementação e estabelecer o nível ótimo. $\mathrm{O}$ menor nível de treonina utilizado no presente trabalho $(0,73 \%)$ está próximo do nível considerado ótimo, levan- 
SOARES et al.

Tabela 2 - Médias de consumo de ração, ganho de peso e conversão alimentar de pintos de corte no período de um a 21 dias de idade de acordo com o nível de treonina da ração

Table 2 - Means of feed intake, weight gain and feed:gain ratio of broiler chicks in the period from 1 to 21 days of age in accordance with the dietary threonine level

\begin{tabular}{|c|c|c|c|c|c|c|}
\hline \multirow[t]{2}{*}{$\begin{array}{l}\text { Nível de treonina (\%) } \\
\text { Threonine level }\end{array}$} & \multicolumn{2}{|c|}{$\begin{array}{l}\text { Consumo de ração (g) } \\
\text { Feed intake }\end{array}$} & \multicolumn{2}{|c|}{$\begin{array}{c}\text { Ganho de peso (g) } \\
\text { Weight gain }\end{array}$} & \multicolumn{2}{|c|}{$\begin{array}{c}\text { Conversão alimentar } \\
\text { Feed/gain ratio }\end{array}$} \\
\hline & Machos & $\begin{array}{l}\text { Fêmeas }^{2} \\
\text { Females }^{2}\end{array}$ & $\begin{array}{c}\text { Machos }^{3} \\
\text { Males }\end{array}$ & $\begin{array}{l}\text { Fêmeas }{ }^{4} \\
\text { Females }\end{array}$ & $\begin{array}{c}\text { Machos }^{5} \\
\text { Males }\end{array}$ & $\begin{array}{l}\text { Fêmeas } \\
\text { Females }^{6}\end{array}$ \\
\hline$\overline{0,73}$ & 1015,9 & 921,2 & 586,9 & 562,0 & 1,73 & 1,64 \\
\hline 0,77 & 961,8 & 954,4 & 597,0 & 550,7 & 1,61 & 1,73 \\
\hline 0,81 & 999,0 & 942,6 & 598,9 & 538,7 & 1,66 & 1,75 \\
\hline 0,85 & 962,1 & 948,1 & 586,5 & 538,3 & 1,64 & 1,76 \\
\hline 0,89 & 1001,0 & 945,9 & 606,8 & 534,6 & 1,65 & 1,76 \\
\hline 0,93 & 1012,0 & 921,6 & 613,5 & 535,3 & 1,65 & 1,72 \\
\hline $\mathrm{CV}(\%)$ & \multicolumn{2}{|c|}{3,17} & \multicolumn{2}{|c|}{2,86} & \multicolumn{2}{|c|}{2,76} \\
\hline
\end{tabular}

${ }^{1}$ Efeito quadrático $(P<0,01) \hat{Y}=3492,14-6109,87 x+3706,97 x^{2}, R^{2}=0,47$.

${ }^{2}$ Efeito quadrático $(P<0,05) \hat{Y}=-952,253+4601,39 x-2779,4 x^{2}, R^{2}=0,74$.

${ }^{3}$ Efeito linear $(P<0,05) \hat{Y}=509,253+107,236 X, R^{2}=0,56$.

${ }^{4}$ Efeito linear $(P<0,05) \hat{Y}=651,075-129,886 x, R^{2}=0,80$.

${ }^{5}$ Efeito quadrático $(P<0,05) \hat{Y}=4,9017-7,6359+4,4623 x^{2}, R^{2}=0,42$.

${ }^{6}$ Efeito quadrático $(P<0,01) \hat{Y}=-4,2736+14,1878 x-8,323 x^{2}, R^{2}=0,94$

${ }^{1}$ Quadract effect $(P<.01)$.

${ }^{2}$ Quadract effect $(P<.05)$.

${ }^{3}$ Linear effect $(P<.05)$.

do em conta, obviamente, o nível de proteína bruta da ração. A formulação de ração basal mais deficiente em treonina foi limitada pelos ingredientes disponíveis.

Outro fator que pode ser considerado é o alto teor de amido na ração basal (34,62\%), que possivelmente influenciou os resultados de desempenho, considerados baixos para o potencial genético da linhagem utilizada. Embora não tenha sido medido parâmetro fisiológico, é possível que tenha ocorrido interação indesejável ou desequilíbrio na atividade das enzimas digestivas, devido ao teor de carboidratos solúveis, influindo negativamente a digestibilidade dos nutrientes nos outros ingredientes.

Além do que foi mencionado, outro fator que pode estar relacionado com o baixo desempenho das aves é a quantidade de sorgo na ração basal $(23,25 \%)$. Embora seja possível a substituição do milho pelo sorgo na alimentação de frangos de corte, neste caso particular pode não ter sido benéfico.

Os níveis de lisina total na ração basal utilizada neste experimento foi 1,24 e 1,12\% de lisina digestível, considerando coeficiente de digestibilidade da lisina de 90,7\%, segundo ROSTAGNO et al. (1996). O nível de $0,86 \%$ de treonina total, estimado por meio do modelo quadrático, de acordo com os resultados de conversão alimentar dos machos, corresponde a $0,73 \%$ de treonina digestível, para um coeficiente de digestibilidade da treonina de $85 \%$, segundo ROSTAGNO et al. (1996). De acordo com estes dados, a proporção de treonina em relação à lisina digestível, dentro do conceito da proteína ideal, é $65 \%$, valor próximo ao sugerido por BAKER e HAN
(1994), ou seja, $67 \%$. Por outro lado, o nível de $0,73 \%$ de treonina total ou $0,62 \%$ de treonina digestível, considerado suficiente para maximizar o desempenho das fêmeas, neste experimento, corresponde à proporção de $55 \%$ em relação à lisina digestível, valor inferior ao sugerido por BAKER e HAN (1994).

Os níveis de treonina não influenciaram os níveis plasmáticos e a excreção de ácido úrico nas aves. Foram encontrados níveis médios de 7,43 e 6,86 mg/100-ml em machos e fêmeas, respectivamente. Estes valores são semelhantes aos encontrados por EMANUEL e HOWARD (1978) e KARAWASA et al. (1973b), que observaram, respectivamente, concentrações de ácido úrico de 7,16e 7,90 mg/100-mL, em aves alimentadas com ração de $20 \%$ de proteína bruta.

As porcentagens de ácido úrico nas excretas das aves são apresentadas na Tabela 3. Não foi observado efeito dos níveis de treonina da ração sobre a excreção de ácido úrico. Entretanto, os machos apresentaram maior excreção de ácido úrico que as fêmeas.

HEVIA e CLIFFORD (1977) observaram que o metabolismo de ácido úrico é influenciado pelo nível de proteína da ração, ou seja, a excreção de nitrogênio urinário aumenta linearmente com o consumo de proteína. No presente experimento não houve variação do nível de proteína bruta da ração e a variação dos níveis de treonina não foi suficiente para acarretar mudanças nas concentrações de ácido úrico no sangue. KARASAWA et al. (1973a) não observaram qualquer efeito estimulador da infusão de treonina sobre a síntese de ácido úrico em galos adultos alimentados com ração de $20 \%$ de proteína bruta. 
126 Rev. bras. zootec.

Tabela 3 - Médias de porcentagem de ácido úrico nas excretas de pintos de corte de acordo com os níveis de treoniana e o sexo

Table 3 - Means of percentage of uric acid in the excreta broiler chicks according to the threonine level and sex

\begin{tabular}{lc}
\hline Treonina $(\%)$ & $\begin{array}{c}\text { Ácido úrico nas excretas }(\%) \\
\text { Excreta uric acid }\end{array}$ \\
\hline 0,73 & 14,08 \\
0,77 & 12,19 \\
0,81 & 12,83 \\
0,85 & 13,43 \\
0,89 & 12,86 \\
0,93 & 13,51
\end{tabular}

$\operatorname{Sexo}(\operatorname{Sex})$

Macho (Male) 13,62

Fêmea (Female) $\quad 12,68$

$\mathrm{CV}(\%)$

${ }^{*}(\mathrm{P}<0,05)$.

\section{Conclusões}

Os níveis de 0,86 e $0,73 \%$ de treonina total e 0,73 e $0,62 \%$ de treonina digestível parecem ser suficientes para ótimo desempenho de machos e fêmeas, respectivamente, no período de 1 a 21 dias de idade.

Os níveis de treonina utilizados não provocaram mudanças nos níveis plasmáticos e na excreção de ácido úrico nas aves.

\section{Referências Bibliográficas}

AUSTIC, R.E., RANGEL-LUGO, M., ESTEVE-GARCIA, E. 1992. Effect of dietary crude protein level on the threonine requirement and the adverse effects of excess dietary threonine. Poult. Sci., 71:36 (Supplement 1).

BAKER, D.H., HAN, Y. 1994. Ideal amino acid profile for chicks during the first three weeks posthaching. Poult. Sci., 73(9):1441-1447.

COLNAGO, G.L. Aminoácidos em rações de frangos e matrizes pesadas. In: CONFERÊNCIA APINCO DE CIÊNCIA E TECNOLOGIA AVÍCOLAS, 1992, Santos. Anais...Santos, APINCO, 1992, p.45-54.

EMMANUEL, B., HOWARD, B.R. 1978. Endogenous uric acid and urea metabolism in the chicken. Br. Poult. Sci., 19(3):295-301.

FERNANDEZ, S.R., AOYAGI, S., HAN, S. et al. 1994. Limiting order of amino acids in corn and soybean for growth on the chick. Poult. Sci., 73(12):1887-1896.

FISCHER JR., A. A., ALBINO, L. F. T., ROSTAGNO, H.S. et al. 1998. Determinação dos coeficientes de digestibilidade e dos valores de aminoácidos digestíveis de diferentes alimentos para aves R.Bras. Zootec., 27(2):307-313.

HAN, Y., BAKER, D. H. 1994. Digestible lysine requirement of male and female broiler chicks during the period three to six weeks posthatching. Poult. Sci., 73(11):1739-1745.

HAN, Y., PARSONS, C.M. 1990. Determination of available amino acids and enrrgy in alfafa meal, feather meal and poultry-by-products meal by various methods. Poult. Sci., 69(9):1554-1562.

HEVIA, P., CLIFOORD, A J. 1977. Protein intake, uric acid metabolism and protein efficiency ratio in growing chicks. $J$. Nut., 67(6):959-964.

HOLSHEIMER, J.P., VEERKAMP, C.H. 1992. Effect of dietary energy, protein and lysine content on performance and yields of two strains of male broiler chicks. Poult. Sci., 71(5):872-879.

KARASAWA,Y., TASAKI, I., YOKOTA, H. et al. 1973a. Comparative effect of intravenously administred nitrogenous compounds on uric acid synthesis in chickens fed a $20 \%$ protein diet. J. Nut., 103(8):1208-1211.

KARASAWA,Y., TASAKI, I., YOKOTA, H. et al. 1973b. Effect of infused glutamine on uric acid synthesis in chicken fed high and low protein diets. J. Nut., 103(4):526-529.

NATIONAL RESEARCH COUNCIL - NRC. 1994. Nutrient reqwuirement for poultry. 9. rev. ed., National Academy Press, Washington, D.C. $155 \mathrm{p}$.

MARQUARDT, R. R. 1983. A simple spectrophotometric method for the direct determination of uric acid in a avian excreta. Poult. Sci., 62(9):2099-2105.

PUPA, J.M. Rações para frangos de corte formuladas com valores de aminoácidos digestiveis verdadiros, determinados com galos cecectomizados:Viçosa, MG: UFV, 1995. 63p. Dissertação (Mestrado em Zootecnia) - Universidade Federal de Viçosa, 1995.

RANGEL-LUGO, M. SU, S.L., AUSTIC, R.E. 1994. Threonine requirement and threonine imbalance in broiler chickens. Poult. Sci., 67(1):108-112.

ROBBINS, K.R. 1987. Threonine requirement of the broiler chick as affected by protein level and source. Poult. Sci., 66(9):1521-1534.

ROGERS, S.R., PESTI, G.M. 1990. The influence of dietary tryptophan on broiler chick growth and lipid metabolism as mediated by dietary protein level. Poult. Sci., 69(5):746-756.

ROSTAGNO, H.S., BARBARINO JR., P., BARBOZA, W. A Exigências nutricionais das aves determinadas no Brasil. In SIMPÓSIO INTERNACIONAL SOBRE EXIGÊNCIAS NUTRICIONAIS DE AVES E SUÍNOS,1996, Viçosa. Anais...Viçosa,1996, p.88.

ROSTAGNO, H.S., SILVA, D.J., COSTA, P.M.A et al. 1992. Composição de alimentos e exigências nutricionais de aves e suínos. Tabelas brasileiras). Viçosa, MG, Imprensa Universitária, 63p.

SMITH JR., N.K., WALDROUP, P. 1988. Investigation of threonine requirements of broiler chicks fed diets based on grain sorghum na soybean meal. Poult. Sci., 67(1):108-112.

UNIVERSIDADE FEDERAL DE VIÇOSA- Central de Processamento de Dados UFV-CPD. SAEG - Sistema para análise estatística e genética. Viçosa, 1982, 59p.

Recebido em: 30/03/98

Aceito em: 04/08/98 